\title{
Desain Modifikasi Gedung Fave Hotel Cilacap Menggunakan Metode Flat Slab
}

\author{
Dody Burhanuddin, Endah Wahyuni dan Djoko Irawan \\ Departeman Teknik Sipil, Fakultas Teknik Sipil, Lingkungan dan Kebumian, \\ Institut Teknologi Sepuluh Nopember \\ e-mail: endah@ce.its.ac.id
}

\begin{abstract}
Abstrak-Gedung Fave Hotel Cilacap adalah gedung hotel dengan 6 lantai yang dibangun di daerah Cilacap yang merupakan kategori risiko gempa tinggi. Modifikasi yang dilakukan diantaranya dengan menambah jumlah lantai menjadi 10 lantai dan menggunakan sistem flat slab dan shearwall sebagai perkuatan dalam menerima beban gempa pada wilayah gempa tinggi. Gedung akan dimodelkan 3 dimensi dengan dibebani beban gravitasi dan gempa. Gedung harus memenuhi persyaratan base shear dan harus memenuhi persyaratan drift untuk memenuhi aspek keamanan gedung.

Dalam modifikasi ini, secara keseluruhan direncanakan dengan Sistem Rangka Pemikul Momen Khusus (SRPMK) dengan dinding geser beton bertulang khusus karena dalam perencanaannya bangunan ini terletak pada zona gempa tinggi sehingga beban lateral akan dipikul oleh dinding struktur sebesar $75 \%$ dari beban lateral keseseluruhan struktur bangunan.

Hasil dari perancangan didapatkan tebal pelat $240 \mathrm{~mm}$, tebal drop panel $160 \mathrm{~mm}$ dengan lebar $300 \mathrm{~cm}$ baik kea rah sumbu $x$ maupun kea rah sumbu $y$, dan dengan penggunaan kolom dengan dimensi $700 \mathrm{~mm} \times 700 \mathrm{~mm}$. Dinding geser dirancang dengan ketebalan $400 \mathrm{~mm}$ dengan menggunakan komponen batas.
\end{abstract}

Kata Kunci-Gedung Fave Hotel Cilacap, Flat Slab, Drop Panel, Shearwall, SRPMK.

\section{PENDAHULUAN}

G EDUNG Fave Hotel Cilacap adalah gedung hotel dengan 6 lantai yang dibangun di daerah Cilacap yang merupakan kategori resiko gempa tinggi. Gedung tersebut dibangun dengan menggunakan beton bertulang biasa (pelat balok, kolom).

Dalam suatu perencanaan gedung, cenderung selalu mengutamakan penghematan-penghematan agar memperoleh keuntungan yang maksimal. Penghematan boleh dilakukan asalkan tidak mengurangi unsur kekuatan gedung tersebut. Salah satu alternatif nya adalah dengan menggunakan metode flat slab [1].

Sistem struktur flat slab terbilang mempunyai kelebihan dibanding dengan sistem struktur beton bertulang biasa, yaitu lebih ekonomis, waktu pelaksanaan yang cepat dan memberikan ruang antar lantai yang lebih besar [2]. Beberapa kelebihan lain penggunaan struktur pelat datar adalah sebagai berikut:

1) Instalasi utilitas mekanikal dan elektrikal yang lebih mudah.

2) Mengurangi tinggi bangunan.

3) Pelaksanaan konstruksi bekisting dan penulangan yang sederhana.
4) Bekistingnya lebih sedikit.

5) Secara estetika dan arsitektur jauh lebih bagus dibandingkan dengan struktur lantai biasa.

6) Lebih ekonomis.

Perancangan dan perilaku struktur flat slab terbukti baik untuk menerima beban gravitasi. Namun, kekurangan dari metode flate slab adalah untuk menerima beban lateral (gempa) belum terbukti ketepatan dan keakuratannya [3]. Bangunan yang didesain menggunakan sistem flat slab hanya bisa didesain pada zona gempa rendah hingga zona gempa menengah. Sehingga perencana harus mengetahui betul zona gempa dari lokasi proyek yang akan dibangun. Untuk mengatasi kekurangan dari sistem flat slab tersebut, maka dalam perencanaannya akan digabungkan dengan dinding geser (shearwall). Gabungan dari sistem flat slab dan dinding geser diharapkan mampu memikul beban akibat gempa rencana pada kategori resiko gempa tinggi. Sehingga bisa mengurangi resiko terjadinya retak pada slab akibat gaya geser atau gaya akibat gempa rencana. Selain itu, dengan menggabungkan kedua sistem ini juga dapat menambah kekuatan bangunan dalam menahan beban rencana [1].

Semula, gedung Fave Hotel Cilacap direncanakan menggunakan struktur beton bertulang biasa (plat, balok dan kolom) atau sistem konvensional. Dalam Studi ini penyusun akan mencoba memodifikasi dengan metode struktur flat slab dan Shear wall.

\section{TINJAUAN PUSTAKA}

A. Umum

Flat slab adalah merupakan konstruksi beton dua arah (twoway slab with drops) yang hanya memiliki unsur horizontal berupa pelat tanpa balok dan ditahan kolom. Sistem flat slab ini mempunyai ciri khusus yaitu tidak adanya balok sepanjang garis kolom dalam (interior), sementara balok-balok tepi sepanjang garis kolom luar (eksterior), bisa jadi ada atau tidak [4]. Kemampuan flat slab untuk menahan gaya geser diperoleh dari salah satu atau kedua hal berikut:

1) Drop Panel yaitu pertambahan tebal pelat di dalam daerah kolom yang berfungsi sebagai penahan gaya geser utama yang menjadi bidang kontak antara pelat dan kolom [5].

2) Kepala Panel (Column Capital) yaitu pelebaran mengecil dari ujung kolom atas yang bertujuan untuk mendapatkan pertambahan keliling sekitar kolom untuk memindahkan geser dari beban lantai dan untuk menambah tebal dengan berkurangnya perimeter di dekat kolom [5]. 


\section{B. Analisa Struktur Flat Slab}

Analisa struktur flat slab dapat dilakukan dengan menggunakan 2 motode yakni: metode desain langsung (direct design method) dan metode portal ekuivalen (equivalent frame method). Pada dasarnya metode portal ekuivalen memerlukan distribusi momen beberapa kali, sedangkan metode desain langsung hanya berupa pendekatan dengan satu kali distribusi momen[6].

1) Metode perencanaan langsung (direct design method)

Metode langsung merupakan metode pendekatan untuk mengevaluasi dan mendistribusikan momen total pada panel slab dua arah. Dengan metode ini diupayakan slab dapat dihitung sebagai bagian dari balok pada suatu portal. Hasil yang diperoleh dengan meggunakan metode pendekatan ini adalah pendekatan momen dan geser dengan menggunakan koefisien-koefisien yang disederhanakan [6].

2) Metode portal ekivalen (equivalent frame method)

Pada metode portal (rangka) ekuivalen menganggap portal idealisasi ini serupa dengan portal aktual sehingga hasilnya akan lebih eksak dan mempunyai batasan penggunaan yang lebih sedikit dibandingkan dengan metode desain langsung. Pada metode portal ekuivalen, struktur dibagi menjadi portal menerus yang berpusat pada kolom dalam masing-masing arah yang saling tegak lurus. Masingmasing portal ini terdiri atas sederetan kolom dan slab lebar dengan balok, apabila ada, diantara garis pusat panel [6].

\section{METODOLOGI}

\section{A. Umum}

Alur pengerjaan Studi ini digambarkan pada diagram alir yang terdapat pada Gambar 1.
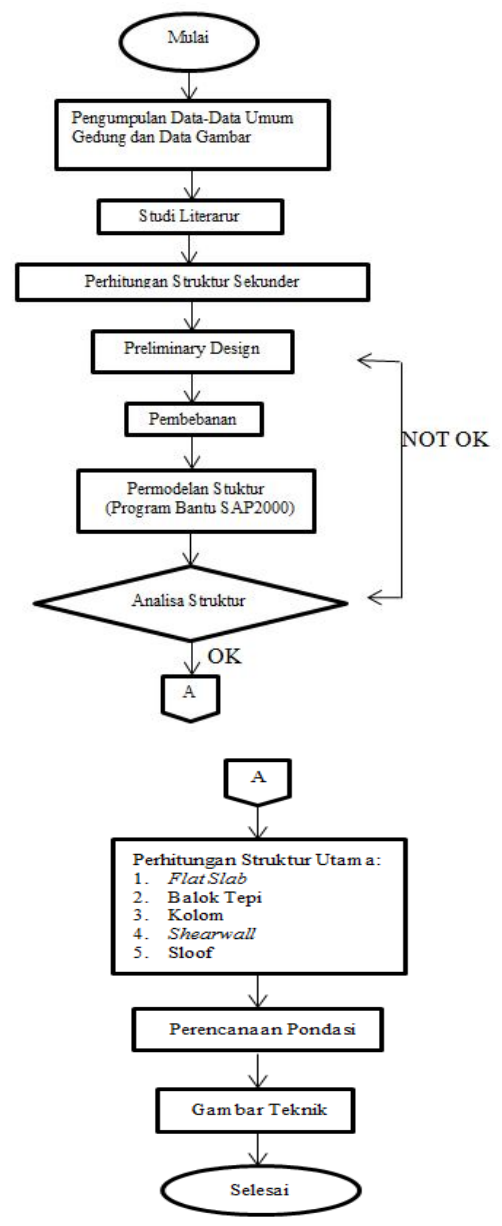

Gambar 1. Diagram alir.

\section{B. Data Bangunan}

Data bangunan adalah sebagai berikut :

1) Nama Gedung Cilacap

2) Lokasi Gedung

3) Lokasi Modifikasi

4) Fungsi

5) Jumlah Lantai

6) Tinggi Bangunan

7) Tinggi Lantai Dasar

8) Tinggi Lantai 2-10

Data Bahan:

1) Kuat Tekan Beton (fc') : $30 \mathrm{Mpa}$

2) Tegangan Leleh Baja (fy): $400 \mathrm{Mpa}$

Denah struktur bangunan dapat dilihat pada Gambar 2.

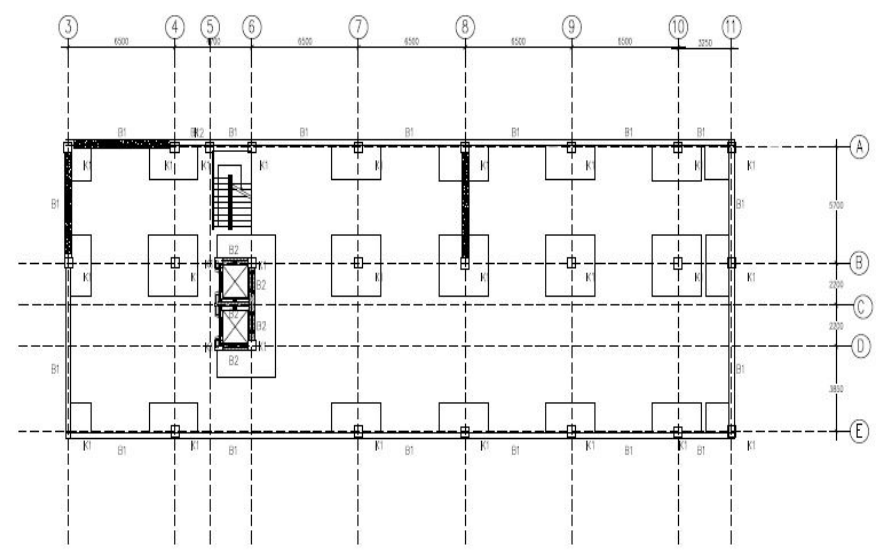

Gambar 2. Denah lantai 3-10.

\section{Kombinasi Pembebanan}

Struktur harus dirancang hingga kuat rencananya sama atau melebihi pengaruh beban-beban terfaktor dengan kombinasi-kombinasi sebagai berikut yang mengacu pada tata cara perencanaan gempa telah ditetapkan pada SNI 2847:2013 pasal 9.2.1 [7]:

$$
\begin{gathered}
\mathrm{U}=1.4 \mathrm{D} \\
\mathrm{U}=1.2 \mathrm{D}+1.6 \mathrm{~L}+0.5 \mathrm{R} \\
\mathrm{U}=1.2 \mathrm{D}+1.6 \mathrm{R}+0.5 \mathrm{~L} \\
\mathrm{U}=1.2 \mathrm{D}+1.0 \mathrm{~W}+1.0 \mathrm{~L}+0.5 \mathrm{R} \\
\mathrm{U}=1.2 \mathrm{D}+1.0 \mathrm{E}+1.0 \mathrm{~L} \\
\mathrm{U}=0.9 \mathrm{D}+1.0 \mathrm{~W} \\
\mathrm{U}=0.9 \mathrm{D}+1.0 \mathrm{E}
\end{gathered}
$$

\section{Permodelan dan Analinsa Struktur}

Analisa struktur dilakukan dengan program bantu SAP2000. Permodelan struktur ini dapat dilihat pada Gambar 3.

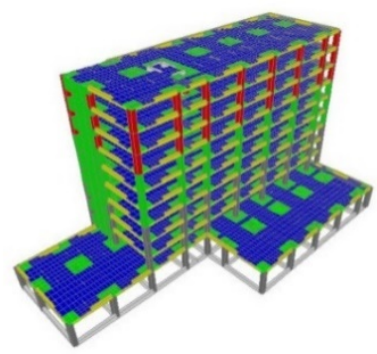

Gambar 3. Permodelan modifikasi struktur gedung. 


\section{HASIL DAN PEMBAHASAN}

A. Perhitungan Sekunder

1) Desain Tangga

Mutu beton (fc')

Mutu baja (fy)

Tinggi antar lantai

$=30 \mathrm{Mpa}$

Panjang bordes

$=400 \mathrm{Mpa}$

$=400 \mathrm{~cm}$

$=280 \mathrm{~cm}$

Lebar bordes

Lebar injakan

Tinggi injakan

$=170 \mathrm{~cm}$

$=30 \mathrm{~cm}$

$=17 \mathrm{~cm}$

$=130 \mathrm{~cm}$

Lebar tangga

$=15 \mathrm{~cm}$

Tebal pelat bordes

Tebal selimut beton

$=15 \mathrm{~cm}$

$=3 \mathrm{~cm}$

a) Penulangan Plat Tangga

Digunakan Penulangan Lentur : $\varnothing 12$-100mm

Digunakan Tulangan Pembagi: $\varnothing 10$ - 200 mm

b) Penulangan Plat Bordes

Digunakan Penulangan Lentur : $\varnothing 12-100 \mathrm{~mm}$

Digunakan Tulangan Pembagi: $\varnothing 10$ - 200 mm

c) Penulangan Balok Bordes Bawah dan Atas

Digunakan Penulangan Lentur Tekan : 2D13

Digunakan Penulangan Lentur Tarik : 2D13

Digunakan Penulangan Sengkang : D10-100

2) Desain Balok Lift

a) Penulangan Balok Lift

Dimensi Balok $\quad: 40 \times 60 \mathrm{~cm}$

Digunakan tulangan lentur tarik : 3D19

Digunakan tulangan lentur tekan : D19

Digunakan Penulangan Sengkang : D10-100

\section{B. Beban Gempa Rencana}

1) Kategori Risiko (I) dan Faktor Keutamaan (Ie)

Berdasarkan pasal 4.1.2 SNI 1726-2012, struktur ini termasuk dalam kategori risiko II dengan faktor keutamaan gempa (Ie) 1 [1][8][9][10].

\section{2) Jenis Tanah}

Berdasarkan hasil tes boring yang dilakukan di lapangan, diperoleh nilai N-SPT tanah rata-rata untuk kedalaman 50 meter yaitu $\mathrm{N}=24,54$. Dengan hasil tersebut, berdasarkan pasal 5.3 SNI 1726-2012, maka kategori tanah yang ada di lapangan merupakan Tanah Sedang (SD) [1][8][9][10].

\section{3) Koefisien Situs}

Berdasarkan pasal 6.2 SNI 1726-2012, koefisien situs ditentukan berdasarkan beberapa parameter, yaitu nilai Ss = 0,996 dan $\mathrm{S} 1=0,386$ dan kelas situs yang berdasarkan jenis tanah [1][8][9][10].

$$
\begin{array}{ll}
\mathrm{Fa}=1,113 & \mathrm{SMS}=1,075 \\
\mathrm{Fv}=1,628 & \mathrm{SM} 1=0,628
\end{array}
$$

4) Parameter Percepatan Spektral Desain

Berdasarkan pasal 6.3 SNI 1726-2012, parameter percepatan spektral desain, yaitu SDS dan SD1 $[1][8][9][10]$.

$$
\begin{aligned}
& \mathrm{S}_{\mathrm{DS}}=0,717 \\
& \mathrm{~S}_{\mathrm{D} 1}=0,419
\end{aligned}
$$

Dengan nilai-nilai tersebut, struktur gedung diklasifikasikan sebagai kategori desain seismik kategori D.

5) Sistem Penahan Gaya Seismik

Untuk kategori desain seismik D, dapat digunakan sistem rangka pemikul momen khusus sebagai sistem strukturnya. dengan dinding geser beton bertulang khusus pada arah $\mathrm{x}$ dan y. Dengan sistem pemikul momen khusus dengan dinding geser beton bertulang khusus maka $75 \%$ gaya gempa akan di pikul dinding geser [8]. Parameter sistem struktur untuk arah $\mathrm{x}$ dan $\mathrm{y}$ dengan dinding geser beton bertulang khusus adalah:

Spektrum Respons Desain

$$
\begin{gathered}
R_{0}=6 \\
\Omega_{0}=2,5 \\
C_{d}=5,5
\end{gathered}
$$

Penentuan nilai $\mathrm{T}_{0}$ dan $\mathrm{T}_{\mathrm{s}}[14]$ :

$$
\begin{gathered}
T_{0}=0,2 \frac{S_{D 1}}{S_{D S}} \\
T_{0}=0,2 \frac{0,419}{0,717} \\
T_{0}=0,117 \\
T_{S}=\frac{S_{D 1}}{S_{D S}} \\
T_{S}=\frac{0,417}{0,717} \\
T_{S}=0,584
\end{gathered}
$$

6) Prosedur Gaya Lateral Ekivalen

Berikut ini akan dihitung koefisien respons seismik, Cs, berdasarkan pasal 7.8.1.1 SNI 1726-2012 [1][8][9][10].

a) Cs maksimum

$$
\begin{gathered}
C s_{\text {maksimum }}=\frac{S_{D S}}{\left(\frac{R}{I}\right)} \\
C s_{\text {maksimum }} \text { arah } x=\frac{0,607}{\left(\frac{6}{1}\right)}=0,1012 \\
C s_{\text {maksimum }} \text { arah } y=\frac{0,607}{\left(\frac{6}{1}\right)}=0,1012
\end{gathered}
$$

b) Cs hitungan

$$
\begin{gathered}
C s_{\text {hasil hitungan }}=\frac{S_{D 1}}{T\left(\frac{R}{I}\right)} \\
C s_{\text {hasil hitungan }}=\frac{0,419}{0.907\left(\frac{7}{1}\right)}=0,066
\end{gathered}
$$

c) Cs minimum

$$
\begin{gathered}
C s_{\text {minimum }}=0,044 S_{D S} I \geq 0,01 \\
C s_{\text {minimum }}=(0,044)(0,717)(1)=0,031
\end{gathered}
$$

Untuk arah $\mathrm{X}$ didapat nilai Cs sebagai berikut:

$$
\begin{array}{ll}
\text { Cs hitungan a } & =0,066 \\
\text { Cs minimum } & =0,031 \\
\text { Cs maksimum } & =0,102
\end{array}
$$

Nilai Cs yang digunakan adalah 0,091 karena Cs hitungan terletak di antara interval antara Cs minimum dan Cs maksimum.

Nilai Cs yang digunakan adalah 0,066 karena Cs hitungan terletak di luar interval antara Cs minimum dan Cs maksimum.

7) Hasil Analisa Struktur

Periode Struktur

Periode struktur (T) yang didapat dari analisis 3 dimensi SAP2000 adalah:

$$
\begin{array}{ll}
\mathrm{T} \text { arah X SAP2000 } & =0,912 \text { detik } \\
\mathrm{T} \text { arah Y SAP2000 } & =0,779 \text { detik }
\end{array}
$$

8) Gaya Geser Dasar Nominal Statik Ekivalen

Didapat nilai gaya lateral ekivalen untuk masing-masing arah adalah:

$$
\begin{gathered}
V_{x, y}=C s_{x} W_{t} \\
V_{x, y}=0,066 \times 1188257,84=738313,12 k N
\end{gathered}
$$

Sedangkan besarnya gaya lateral akibat respons dinamik (Vt) yang dihasilkan SAP2000 adalah:

$$
\begin{gathered}
V t_{x}=24918,42 k N \\
V t_{y}=235461,52 k N
\end{gathered}
$$


Berdasarkan pasal 7.9.4.1 SNI 1726-2012, nilai akhir respons dinamik struktur gedung terhadap pembebanan gempa nominal akibat pengaruh gempa rencana dalam suatu arah tertentu, tidak boleh diambil kurang dari 85\% nilai respons ragam yang pertama [1][8][9][10].

Maka untuk arah x dan y akan dikalikan faktor skala:

$$
\begin{gathered}
\text { Faktor skala }=\frac{0,85 V x}{V_{t x}} \geq 1 \\
\text { Faktor skala }=\frac{627566,165}{29418,42} \geq 1 \\
\text { Faktor skala arah } x=2,12793
\end{gathered}
$$

$$
\begin{gathered}
\text { Faktor skala }=\frac{0,85 V y}{V_{t y}} \geq 1 \\
\text { Faktor skala }=\frac{627566,165}{235460,88} \geq 1 \\
\text { Faktor skala arah } y=2,66527
\end{gathered}
$$

\section{Perhitungan Struktur Primer}

\section{1) Perencanaan Pelat}

Untuk perancangan tulangan arah $x$ momen yang digunakan adalah $\mathrm{M}_{1-1}$ sedangkan untuk arah $y$ momen yang digunakan adalah $\mathrm{M}_{2-2}$. Berikut adalah data-data perancangan pelat:

Tebal pelat $=240 \mathrm{~mm}$

Tebal drop panel $=160 \mathrm{~mm}$

Dimensi drop panel $=300 \mathrm{~cm} \times 300 \mathrm{~cm} \times 160 \mathrm{~cm}$

Mutu beton (f'c) $=30 \mathrm{Mpa}$

Mutu baja (fy) $=400 \mathrm{Mpa}$

Tulangan tarik= D25 mm

Momen yang terjadi pada pelat merupakan hasil yang didapatkan dari program bantu SAP2000. Besar momen pelat dapat dilihat pada Tabel 1 .

Tabel 1.

Momen pelat

\begin{tabular}{crrcr}
\hline \hline & \multicolumn{3}{c}{ Momen 1-1 KNm } & \multicolumn{2}{c}{ Momen 2-2 KNm } \\
\cline { 2 - 5 } & kolom & tengah & kolom & \multicolumn{1}{c}{ tengah } \\
\hline Tumpuan & 490,848 & 170,487 & 574,688 & 161,378 \\
Lapangan & 78,777 & 103,994 & 116,791 & 96,493 \\
\hline \hline
\end{tabular}

Hasil perhitungan penulangan pelat dapat dilihat pada Tabel 2.

Tabel 2.

Penulangan Pelat

\begin{tabular}{cccccc}
\hline \hline Arah Penulangan & \multicolumn{2}{c}{ Posisi Tulangan } & \multicolumn{3}{c}{ Tulangan Pelat } \\
\hline & Tumpuan & Atas & D25 & - & 100 \\
& Lajur Kolom & Bawah & D25 & - & 300 \\
& Lapangan & Atas & D19 & - & 400 \\
Arah X & Lajur Kolom & Bawah & D19 & - & 200 \\
& Tumpuan & Atas & D19 & - & 100 \\
& Lajur Tengah & Bawah & D19 & - & 250 \\
& Lapangan & Atas & D19 & - & 300 \\
& Lajur Tengah & Bawah & D19 & - & 200 \\
& Tumpuan & Atas & D25 & - & 100 \\
& Lajur Kolom & Bawah & D25 & - & 300 \\
& Lapangan & Atas & D19 & - & 400 \\
Arah Y & Lajur Kolom & Bawah & D19 & - & 150 \\
& Tumpuan & Atas & D19 & - & 100 \\
& Lajur Tengah & Bawah & D19 & - & 300 \\
& Lapangan & Atas & D19 & - & 400 \\
& Lajur Tengah & Bawah & D19 & - & 150 \\
\hline \hline
\end{tabular}

2) Desain Balok Tepi

Data-data desain yang dibutuhkan dalam perhitungan balok primer:

Dimensi Balok

Bentang Balok

$=400 / 600 \mathrm{~mm}$

Mutu Beton $\left(f^{\prime}{ }_{c}\right)$

$=8250 \mathrm{~mm}$

$=30 \mathrm{MPa}$

Selimut Beton
Diameter Tul. Utama (Ø)
$=25 \mathrm{~mm}$
Mutu baja $\left(f_{\mathrm{y}}\right)$
$=400 \mathrm{MPa}$
Diameter Tul. Sengkang $(\varnothing)$
$=12 \mathrm{~mm}$
Mutu baja $\left(f_{\mathrm{y}}\right)$
$=400 \mathrm{MPa}$

Berdasarkan perencanaan penulangan digunakan penulangan akibat kondisi setelah komposit, yaitu:

Tulangan lentur tumpuan: 8D25(+) dan 6D25(-)

Tulangan lentur lapangan: 4D25(+) dan 6D25(-)

Detail penulangan balok tepi dapat dilihat pada Gambar 4.

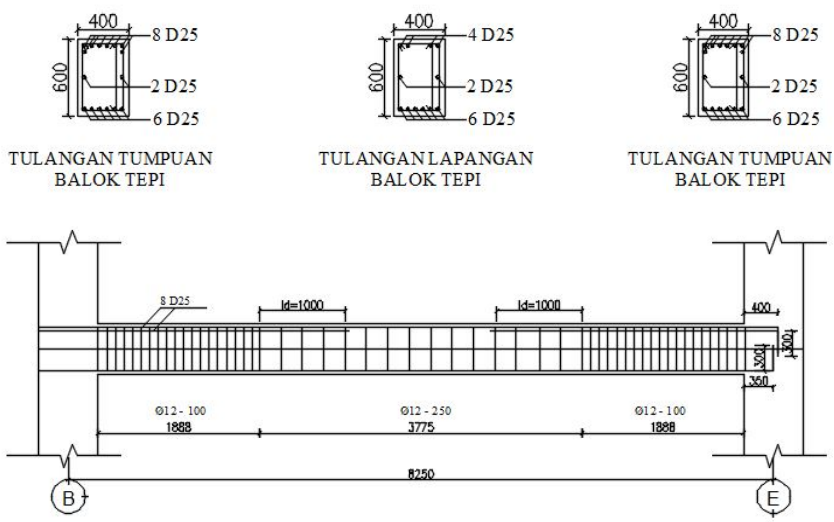

Gambar 4. Detail balok tepi.

3) Perencanaan Kolom

Pada desain modifikasi terdapat jenis kolom, yaitu $\mathrm{K} 1$ = $700 \times 700 \mathrm{~mm}$.

Berdasarkan perencanaan penulangan digunakan penulangan, yaitu:

Tulangan lentur: 16D25

Tulangan geser: 3 kaki D16 - 100 (sepanjang 1 meter dari masing-masing tumpuan) dan 2D16-150 di luar 1 meter tersebut.

4) Perencanaan Dinding Geser

$\begin{array}{ll}\text { Tinggi Dinding, }\left(h_{w}\right) & =31500 \mathrm{~mm} \\ \text { Tebal Dinding, }(h) & =400 \mathrm{~mm} \\ \text { Panjang Dinding arah x, }\left(l_{w \mathrm{x}}\right) & =10000 \mathrm{~mm} \\ \text { Mutu Beton, }\left(f^{\prime} \mathrm{c}\right) & =30 \mathrm{MPa} \\ \text { Mutu Baja, }(f y) & =400 \mathrm{MPa} \\ \text { Tulangan Vertikal } & =\mathrm{D} 19-150 \\ \text { Tulangan Horizontal } & =\mathrm{D} 13-200\end{array}$

5) Perencanaan Sloof

Data perencanaan:

Dimensi sloof $\quad=500 \times 700$

Panjang sloof $\quad=8.25 \mathrm{~m}$

Mutu beton $\left(f^{\prime} c\right) \quad=30 \mathrm{MPa}$

Diameter Tul. Utama (D) $=19 \mathrm{~mm}$

Mutu Baja $(f y) \quad=400 \mathrm{MPa}$

Elastisitas $(E s) \quad=200000 \mathrm{MPa}$

Selimut beton $\quad=40 \mathrm{~mm}$

Tulangan lentur tumpuan: 4D19(+) dan 3D19(-)

Tulangan lentur lapangan: 2D19(+) dan 3D19(-)

D. Perhitungan Pondasi

Pada perencanaan pondasi gedung ini, digunakan pondasi tiang pancang jenis spun pile Produk dari PT. Wijaya Karya Beton.

Diameter tiang pancang, $\mathrm{d} \quad=60 \mathrm{~mm}$

Thickness $\quad=100 \mathrm{~mm}$

Kelas $\quad=\mathrm{A} 1$

Bending momen crack $\quad=17 \mathrm{tm}$

Bending momen ultimate $\quad=25,5 \mathrm{tm}$

Allowable axial $\quad=252,7$ ton 
Keliling tiang pancang $(A s)$

Luas tiang pancang $(A p)$

$$
\begin{aligned}
& =\pi \times d=188,496 \mathrm{~cm} \\
& =1 / 4 \times \pi \times d^{2} \\
& =1 / 4 \times \pi \times 60^{2}=2826 \mathrm{~cm}^{2}
\end{aligned}
$$

Denah pondasi dapat dilihat pada Gambar 5.

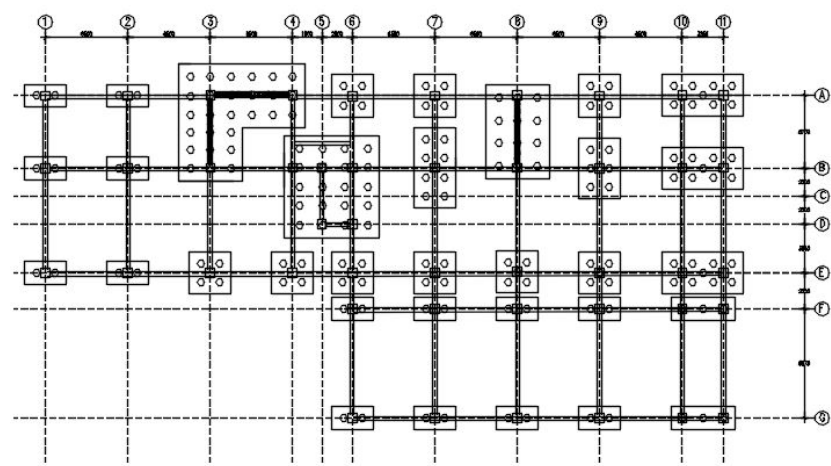

Gambar 5. Denah pondasi.

\section{KESIMPULAN}

Hasil perencanaan struktur Gedung Fave Hotel Cilacap menggunakan metode flat slab dengan mutu beton $30 \mathrm{Mpa}$ dan mutu baja 400 Mpa didapatkan hasil perencanaan sebagai berikut:
1) Tebal Pelat Lantai
$=24 \mathrm{Cm}$
2) Pelat Arah Sumbu $X$
Tumpuan Jalur Kolom
Lapangan Jalur Kolom
$=\mathrm{D} 25-100 \mathrm{~mm}$ (atas)
= D25-300 mm (bawah)
$=\mathrm{D} 19-400 \mathrm{~mm}$ (atas)
= D19-200 mm (bawah)
= D19-100 mm (atas)
Tumpuan Jalur Tengah
= D19-250 mm (bawah)
Lapangan Jalur Tengah
$=\mathrm{D} 19-300 \mathrm{~mm}$ (atas)
= D19-200 mm (bawah)
3) Pelat Arah Sumbu Y
Tumpuan Jalur Kolom
Lapangan Jalur Kolom
$=\mathrm{D} 25-100 \mathrm{~mm}$ (atas)
= D25-300 $\mathrm{mm}$ (bawah)
$=\mathrm{D} 19-400 \mathrm{~mm}$ (atas)
= D19-150 mm (bawah)
Tumpuan Jalur Tengah

Lapangan Jalur Tengah

4) Dimensi Drop Panel Tulangan Geser

5) Dimensi Kolom Tulangan Lentur Tulangan Geser

6) Dimensi Dinding Geser Tulangan Vertikal Tulangan Horizontal

7) Dimensi Pondasi Tiang Pancang Diameter Tiang Pancang $=60 \mathrm{~cm}$ Jumlah Tiang Pancang

$=121($ Kolom $)$

$=30$ Titik (Shear Wall)

\section{DAFTAR PUSTAKA}

[1] P. Studi, S. Lintas, J. Jurusan Teknik, S. Fakultas, T. Sipil, and D. Perencanaan, "Perencanaan Modifikasi Struktur Gedung Rumah Susun dengan Menggunakan Sistem Flat Slab dan Dinding Geser.”

[2] R. Institut Teknologi Bandung. Fakultas Teknik Sipil \& Perencanaan., B. Budiono, A. Surono, and I. Pane, "Studi Eksperimental Perilaku Siklis Flat Slab Beton Mutu Sangat Tinggi,” J. Civ. Eng., vol. 21, no. 2, pp. 139-146, 2014.

[3] L. HEMAWAN and LUKMAN, "Studi Perumusan Lebar Efektif Pelat pada Struktur Flat Plate Akibat Beban Gempa,” Undergrad. Theses, Civ. Eng. RSS 624.177 65 Hem s, 2007, 2008.

[4] R. Institut Teknologi Bandung. Fakultas Teknik Sipil \& Perencanaan., B. Budiono, I. Imran, and A. Sofwan, Studi Eksperimental Perilaku Hubungan Pelat-Kolom terhadap Kombinasi Gravitasi dan Lateral Siklis, vol. 19, no. 3. 2012.

[5] H. Sulistio and S. Adi, "Alternative Study on Flat Slab Building of Grand Sawit Hotel of Samarinda by Using Equivalent Portal Methods," J. Tek. Sipil dan Arsit.

[6] H. Deshpande, R. Joshi, and P. Bangar, "Design Considerations for Reinforced Concrete Flat Slab Floor System,” 2014.

[7] Badan Standardisasi Nasional, "Persyaratan Beton Struktural untuk Bangunan Gedung,” 2013.

[8] B. S. Nasional, "Tata Cara Perencanaan Ketahanan Gempa untuk Struktur Bangunan Gedung dan Non-Gedung,” 2012.

[9] Trie Sony Kusumowibowo, "Modifikasi Perencanaan Gedung Rumah Sakit Umum Daerah Kota Jakarta dengan Metode Pracetak.”

[10] K. I. Klana, "Modifikasi Perencanaan Struktur Gedung Ibis Styles Hotel Tanah Abang Jakarta Pusat Dengan Metode Beton Pracetak,” Jul. 2017. 